\title{
Loss of function of Notch1 identifies a poor prognosis group of early stage hepatocellular carcinoma following hepatectomy
}

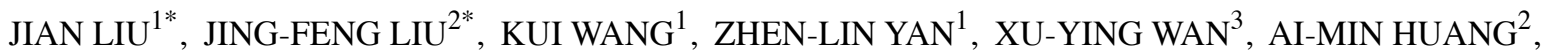 \\ YI-ZHOU WANG ${ }^{1}$, JUN LI ${ }^{1}$, YONG XIA ${ }^{1}$, LE-HUA SHI ${ }^{1}$, BING-HUA JIAO ${ }^{4}$, YONGJIE ZHANG ${ }^{1}$ and FENG SHEN ${ }^{1}$ \\ ${ }^{1}$ Department of Hepatic Surgery, Eastern Hepatobiliary Surgery Hospital, Second Military Medical University, Shanghai; \\ ${ }^{2}$ Department of Hepatobiliary Surgery, The First Affiliated Hospital, Fujian Medical University, Fuzhou, Fujian; \\ ${ }^{3}$ Department of Clinical Database, Eastern Hepatobiliary Surgery Hospital, and ${ }^{4}$ Department of Biochemistry \\ and Molecular Biology, Second Military Medical University, Shanghai, P.R. China
}

Received July 15, 2015; Accepted August 10, 2015

DOI: 10.3892/or.2015.4300

\begin{abstract}
Notch1 has previously been implicated in the carcinogenesis of hepatocellular carcinoma (HCC). The present study aimed to investigate the prognostic value of Notch1 in early stage HCC patients after hepatectomy. The differential expression of Notch1 in paired tumor and non-tumorous tissue was evaluated by RT-PCR, western blotting and immunohistochemistry. The correlation between Notch1 expression and the surgical outcome of patients at BCLC stage $0 / A$ and its $\leq 5 \mathrm{~cm}$ subgroup was retrospectively investigated in 206 patients from the Eastern Hepatobiliary Surgery Hospital (training cohort), and prospectively validated in 185 patients from the same center and retrospectively verified in 129 patients from the Fujian Medical University (validation cohort 1 and 2, respectively). Compared with paired non-tumorous tissues, loss of Notch1 was observed in tumor tissue. Patients with normal Notch1 had better prognosis than those with loss of Notch1 in the training cohort and $\leq 5 \mathrm{~cm}$ subgroup (time to recurrence: $38.5 \pm 6.1 \mathrm{vs}$. $16.0 \pm 3.2$ months, $\mathrm{P}<0.001$ and $53.0 \pm 6.1$ vs. $21.7 \pm 3.5$ months, $\mathrm{P}=0.004 ; 1-, 3-, 5$-year survival rates: 91,64 and $49 \%$ vs. 73,31 and $22 \%, \mathrm{P}<0.001$ and $93,71,57 \%$ vs. $76,39,24 \%, \mathrm{P}<0.001$ ). Notch1 expression was an independent factor for recurrence
\end{abstract}

Correspondence to: Professor Feng Shen or Porfessor Yongjie Zhang, Department of Hepatic Surgery, Eastern Hepatobiliary Surgery Hospital, Second Military Medical University, Shanghai 200438, P.R. China

E-mail: shenfengehbh@sina.com

E-mail: yjoy005@sina.com

${ }^{*}$ Contributed equally

Abbreviations: HCC, hepatocellular carcinoma; AFP, $\alpha$-fetoprotein; BCLC, Barcelona-Clinic-Liver-Cancer; TT, tumor tissue; NTT, non-tumorous tissue; TTR, time to recurrence; OS, overall survival; TMA, tissue microarray; IHC, immunohistochemistry; PVTT, portal vein tumor thrombus; MVI, microvascular invasion

Key words: early hepatocellular carcinoma, Notch1, BCLC staging system, hepatectomy, prognosis and survival (hazard ratio: 1.901, 2.154; 2.038 and 2.337). Moreover, Notch1 status affected early tumor recurrence, as the 2 -year recurrence rate was 61.2 vs. $26.9 \%(\mathrm{P}<0.001)$ and 51.2 vs. $21.3 \%(\mathrm{P}=0.002)$ in tumors with reduced or increased Notch1 expression in this cohort and subgroup. These results were fully confirmed by the study in our prospective and retrospective validation cohorts. The status of Notch1 is useful for predicting the prognosis of patients with early stage HCC undergoing hepatectomy.

\section{Introduction}

Hepatocellular carcinoma (HCC) is one of the most prevalent cancers and the fifth leading cause of cancer-related deaths worldwide $(1,2)$. Although partial hepatectomy is considered as one of the first line treatments for patients with early stage HCC, the outcome is far from satisfactory due to a high recurrence rate, which is up to $60 \%$ at postoperative five years (3-7). In clinical practice, it is difficult to predict the prognosis of early stage HCC patients due to similarities in clinicopathologic characteristics. Although great efforts have been made in prognostic biomarker investigation, the optimal candidate with clinical applicability is still lacking but urgently required (7-12).

Notch1 is a member of the Notch family and its association with human malignancy was first established in T-cell acute lymphoblastic leukemia (13-16). It has been reported that aberrant expression of Notch1 may contribute to carcinogenesis in additional types of malignancies (17-19). Recent studies also indicate that Notch1 may play an important role in hepatic carcinogenesis (20-22). Qi et al reported that upregulated Notch1 in the SMMC-7721 cell line induced cell cycle arrest and inhibited cell growth (20). They also found that Notch1 sensitized tumor necrosis factor-related apoptosis inducing ligand (TRAIL)-induced apoptosis in HCC cell lines (21). A previous study revealed that $\mathrm{HBx}$ overexpression in liver cancer cells decreased Notch1 signaling activity, promoting cell proliferation and inducing cell cycle progression, while blunting senescence-like growth arrest in vitro and in vivo (22). These studies have suggested an important role of Notch1 as a tumor suppressor in the carcinogenesis of liver 
cancer. However, the relationship between Notch1 expression and disease outcome has not yet been evaluated.

We examined the differential expression of Notch1 in paired tumor tissue (TT) and non-tumorous tissue (NTT). The association of Notch1 expression with outcome of early stage (BCLC stage 0 and A) HCC patients, as well as their $\leq 5 \mathrm{~cm}$ subgroups (stage 0 and $\leq 5 \mathrm{~cm}$ stage $\mathrm{A}$ ) was analyzed. To the best of our knowledge, this is the first study exploring the clinical significance of Notch1 in HCC.

\section{Materials and methods}

Patients. We determined the differential expression of Notch1 in paired TT and NTT in 40 HCC patients, who were randomly selected from the Eastern Hepatobiliary Surgery Hospital (EHBH) between January and February 2004. All resected fresh TT and NTT samples were subjected to RT-PCR and western blot analysis.

We then investigated the relationship between Notch1 expression in TT and surgical outcome. The inclusion criteria required patients to have BCLC stage 0 or A HCCs with Child-Pugh A liver function, to have received curative hepatectomy and no evidence of distant metastasis, image visible ascites or severe varices, and to have no history of preoperative anticancer therapy. The definition of curative hepatectomy was described in our previous studies (23). Patients were excluded from the present study if they had a history of another malignancy or died from severe postoperative complications. According to the criteria, 206 patients undergoing hepatectomy between October 1997 and September 2002 were randomly retrieved from a database of the EHBH which was recognized as the training cohort. Formalin-fixed, paraffin-embedded specimens, clinicopathologic and follow-up data were obtained for immunohistochemistry (IHC) staining and prognostic analyses.

For validating the results from the training cohort, we prospectively collected 185 consecutive patients from the EHBH between March and September 2004, as validation cohort 1. Another independent cohort of 129 consecutive patients from the First Affiliated Hospital of Fujian Medical University between September 2001 and March 2009, was retrospectively recruited as validation cohort 2 . Identical inclusion and exclusion criteria were used in the validation cohorts of patients as compared with the patients in the training cohort.

The clinical staging was determined by the BarcelonaClinic-Liver-Cancer (BCLC) and Tumor-Node-Metastasis (TNM) classification systems $(7,8,24)$. According to AASLD guidelines, the BCLC stage 0 and A was defined as early stage of HCC in the present study $(7,8)$. The present study protocol was approved by the Institutional Review Board of the Eastern Hepatobiliary Surgery Hospital and the Institutional Review Board of the First Affiliated Hospital of Fujian Medical University. Written informed consent for each patient was obtained before surgery.

RNA analysis. Total RNA from 40 paired TT and NTT was isolated using TRIzol (Life Technologies, Inc., Rockville, MD, USA) according to the manufacturer's instructions. Reverse transcription was performed on $1 \mu \mathrm{g}$ of total RNA from each sample using oligo(dT) $)_{18}$ primers and 200 units of SuperScript II (Life Technologies) for extension.
The primers used in semi-quantitative PCR and real-time PCR were as follows: Notch1 sense, 5'-CCGCAGTTGTGCTC CTGAA-3' and Notch1 antisense, 5'-ACCTTGGCGGTCTCG TAGCT-3'; GAPDH sense, 5'-GTTGGAGGTCGGAGTCAA CGGA-3' and antisense, 5'-GAGGGATCTCGCTCCTGGAG GA-3'. GAPDH was used as an internal quantitative control. Semi-quantitative PCR amplification was performed with 1.25 units Ex Taq polymerase (Takara, Dalian, China). All of the PCR products were resolved on a $2 \%$ agarose gel containing ethidium bromide. Real-time PCR was performed using the SYBR-Green detection of PCR products in real time with the LightCycler (Roche Diagnostics, Meylan, France). The analyses were carried out according to the manufacturer's instructions. The relative expression level of Notch1 was obtained as a ratio normalized to GAPDH expression level. A no-template negative control was included in each experiment. All experiments were repeated three times, and the results are presented as the mean value.

Western blot analysis. The tissues were lysed in T-PER Tissue Protein Extraction Reagent (Pierce, Rockford, IL, USA) containing proteinase inhibitors (Calbiochem, San Diego, CA, USA). The extracts were collected and centrifuged at $12,000 \mathrm{x} \mathrm{g}$ for $5 \mathrm{~min}$. The protein concentrations were determined using the BCA protein assay (Pierce), according to the manufacturer's instructions. Total proteins $(20 \mu \mathrm{g})$ from whole lysates were boiled for 5 min in $1 \mathrm{X}$ SDS buffer, resolved by $8 \%$ SDS-PAGE and transferred to nitrocellulose membranes. Membranes were blocked with $0.1 \mathrm{M}$ Tris $(\mathrm{pH} 7.5), 0.9 \% \mathrm{NaCl}$ and $0.05 \%$ Tween-20 (TBST) containing 10\% non-fat milk powder and then incubated with the appropriate primary antibody (1:200; Notch1 and $\beta$-actin; Santa Cruz Biotechnology, Santa Cruz, CA, USA), followed by incubation with anti-goat (rabbit) horseradish peroxidase-conjugated antibody (1:5,000; Santa Cruz Biotechnology). Finally, the proteins were detected using the Western Blotting Luminol reagent (Santa Cruz Biotechnology).

Tissue microarray and immunohistochemical staining. Tissue microarrays (TMAs) were constructed as previously described (23). The first antibody was purchased from Santa Cruz Biotechnology (1:50). Immunohistochemical staining was performed using the Dako Envision Plus System (Dako, Carpinteria, CA, USA) according to the manufacturer's instructions. Appropriate negative and positive controls were used. The tissue was evaluated as positive for Notch1 staining when there were $>10 \%$ of tumor cells demonstrating cytoplasmic and/or nuclear immunoreaction deposits. The sections were scored with a four-tier scale: 0 , negative $(0-10 \%)$, 1 , weak signal (>10-20\%), 2 , intermediate signal (>20-50\%) and 3 , strong signal $(>50 \%) .0$ and 1 were defined as loss of Notch1, while 2 and 3 were defined as normal Notch1. All sections were independently scored by two observers who did not have any prior knowledge of the clinicopathological data. The concordance between scores from different sections of the same tumor was $>90 \%$. All discrepancies in scoring were reviewed and a consensus was reached.

Follow-up. Patients were examined every 2-3 months during the first two years and every 3-6 months from the third year after surgery. The standard examination of each visit and diag- 
Table I. Characteristics of the patients in the three cohorts.

\begin{tabular}{|c|c|c|c|c|c|}
\hline Variables & $\begin{array}{l}\text { Training cohort } \\
\qquad(n=206)\end{array}$ & $\begin{array}{l}\text { Validation cohort } 1 \\
\qquad(\mathrm{n}=185)\end{array}$ & P-value ${ }^{b}$ & $\begin{array}{l}\text { Validation cohort } 2 \\
\qquad(\mathrm{n}=129)\end{array}$ & P-value \\
\hline Age, in years, median (range) & $50(15-74)$ & $47(21-77)$ & $0.149^{\mathrm{a}}$ & $53(14-78)$ & $0.029^{\mathrm{a}}$ \\
\hline Female, n (\%) & $23(11.2)$ & $29(15.7)$ & 0.190 & $23(17.8)$ & 0.085 \\
\hline HBsAg, n (\%) & $168(81.6)$ & $163(88.1)$ & 0.073 & $108(83.7)$ & 0.612 \\
\hline $\mathrm{HBe} A g, \mathrm{n}(\%)$ & 18 (8.7) & $36(19.5)$ & 0.002 & $22(17.1)$ & 0.022 \\
\hline Liver cirrhosis, n (\%) & $194(94.2)$ & $121(65.4)$ & $<0.001$ & 99 (76.7) & $<0.001$ \\
\hline Multiple tumors, n (\%) & $52(25.2)$ & $33(17.8)$ & 0.076 & $49(38.0)$ & 0.013 \\
\hline Complete encapsulation, n (\%) & $60(29.1)$ & $43(23.2)$ & 0.187 & $30(23.3)$ & 0.238 \\
\hline Microvascular invasion, n (\%) & $141(68.4)$ & $99(53.5)$ & 0.002 & $56(43.4)$ & $<0.001$ \\
\hline $\mathrm{AFP} \geq 20 \mu \mathrm{g} / \mathrm{l}, \mathrm{n}(\%)$ & $142(68.9)$ & $128(69.2)$ & 0.956 & $83(64.3)$ & 0.384 \\
\hline Diameter $\leq 5 \mathrm{~cm}, \mathrm{n}(\%)$ & $102(49.5)$ & $75(40.5)$ & 0.075 & $80(62.0)$ & 0.025 \\
\hline \multicolumn{6}{|l|}{ Differentiation, n (\%) } \\
\hline $\mathrm{I}-\mathrm{II}$ & $35(17.0)$ & $42(22.7)$ & 0.156 & $39(30.2)$ & 0.004 \\
\hline III-IV & $171(83.0)$ & $143(77.3)$ & & $90(69.8)$ & \\
\hline Transfusion, n (\%) & $70(34.0)$ & $38(20.5)$ & 0.003 & $19(14.7)$ & $<0.001$ \\
\hline \multicolumn{6}{|l|}{ Laboratory values, median (range) } \\
\hline Total bilirubin, $\mu \mathrm{mol} / 1$ & $12.2(3.0-48.9)$ & $13.6(3.7-64.6)$ & $0.011^{\mathrm{a}}$ & $15.5(3.4-147.7)$ & $<0.001^{\mathrm{a}}$ \\
\hline Albumin, $\mathrm{g} / \mathrm{l}$ & $42.1(31.5-54.3)$ & $40.2(28.7-50.6)$ & $<0.001^{\mathrm{a}}$ & $41.0(31.4-51.4)$ & $<0.001^{\mathrm{a}}$ \\
\hline Platelets, $10^{9} / 1$ & $120.5(20-342)$ & $146.0(24-468)$ & $<0.001^{\mathrm{a}}$ & Not collected & \\
\hline Prothrombin time, sec & $12.9(9.7-21.1)$ & $13.5(9.8-18.5)$ & $<0.001^{\mathrm{a}}$ & Not collected & \\
\hline GGT, U/1 & $56.7(10.0-391.0)$ & $75.0(11.0-576.0)$ & $0.001^{\mathrm{a}}$ & Not collected & \\
\hline ALP, U/1 & $133.0(35-553)$ & $94.0(38-377)$ & $<0.001^{\mathrm{a}}$ & Not collected & \\
\hline ALT, U/l & $47.5(17.0-699.0)$ & $49.7(8.2-104.0)$ & $0.356^{\mathrm{a}}$ & $45.0(7.0-182.0)$ & $0.292^{\mathrm{a}}$ \\
\hline
\end{tabular}

HBsAg, hepatitis B surface antigen; HBeAg, hepatitis B e antigen; AFP, $\alpha$-fetoprotein; GGT, $\gamma$-glutamyl transferase; ALP, alkaline phosphatase; ALT, alanine aminotransferase. ${ }^{\mathrm{a}}$ Mann-Whitney test; ${ }^{\mathrm{b}} \mathrm{P}$-value, training cohort vs. validation cohort 1 ; ${ }^{\mathrm{c}} \mathrm{P}$-value, training cohort vs. validation cohort 2 .

nosis of recurrence were described in our previous study (23). Patients with HCC recurrence received further treatments according to the tumor location, number of recurrent lesions, evidence of portal hypertension and hepatic compensatory function.

Time to recurrence (TTR) and overall survival (OS) were considered as primary endpoints of the present study. TTR was calculated from the date of resection to the date when tumor recurrence was diagnosed. OS was defined as the interval between surgery and death or last observation for surviving patients (25).

Statistical analysis. Analysis was performed with SPSS, version 10.0 for Windows (SPSS, Inc.); the $\chi^{2}$ or Fisher's exact tests were used to compare qualitative variables, while continuous variables were compared using the Student's t-test or Mann-Whitney test for variables with an abnormal distribution. Receiver operating characteristic curve analysis was used to determine the optimal cut-offs of continuous variables. Expression of Notch1 in TT and paired NTT was compared by the Wilcoxon test. Survival curves were calculated by the Kaplan-Meier method and compared using the log-rank test. The Cox proportional hazards model was used to determine the independent factors based on the variables selected by the univariate analysis. $\mathrm{P}<0.05$ was considered to indicate a statistically significant result.

\section{Results}

Characteristics of the patients. Table I summarizes the clinicopathological characteristics of all the patients. The 1-, 3- and 5-year recurrence and survival rates were: 27,59 and $74 \%$, and 82,49 and $36 \%$ in the training cohort; 33,63 and $64 \%$, and 78 , 52 and $49 \%$ in the validation cohort $1 ; 31,54$ and $57 \%$, and 84 , 58 and $45 \%$ in the validation cohort 2.

Notchl expression in TT and matched NTT. Compared with NTT, TT showed loss of Notch1 mRNA and protein by real-time RT-PCR, semi-quantitative RT-PCR and western blotting (Fig. 1A-C). Similarly, TT displayed a relatively weaker immunostaining of Notch1 when compared with NTT (Fig. 1D-G). As shown in Table II, the expanded IHC investigation suggested that Notch1 expression in TT was significantly lower than that in NTT in the training cohort $(\mathrm{P}<0.001)$, which was verified by two validation cohorts ( $\mathrm{P}<0.001$ for both). 


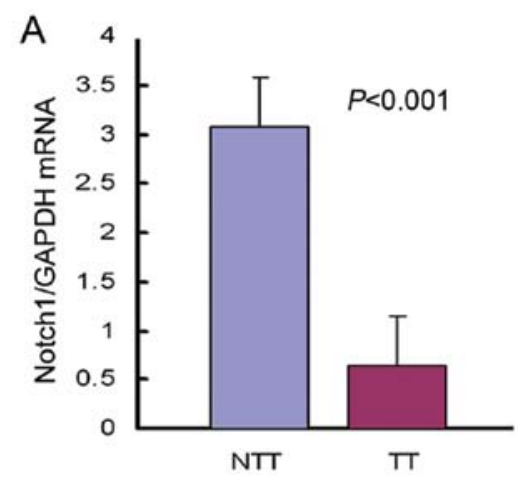

D

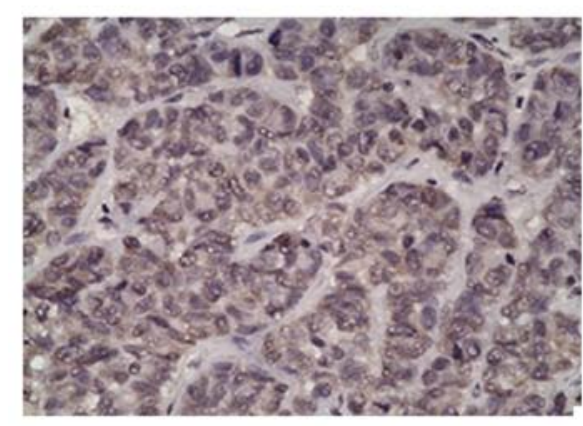

$\mathrm{F}$

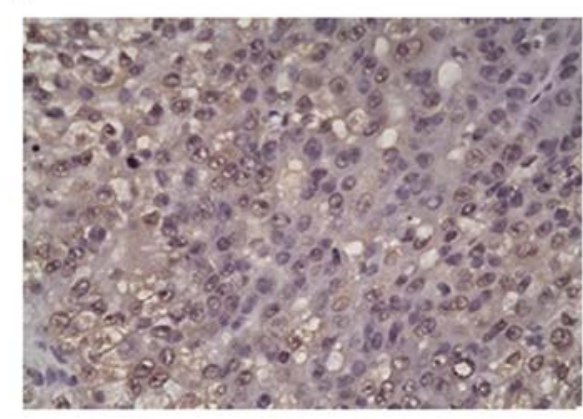

B NTT TT NTT TT NTT TT NTT TT

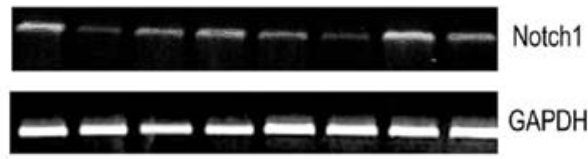

C TT NTT TT NTT TT NTT TT NTT

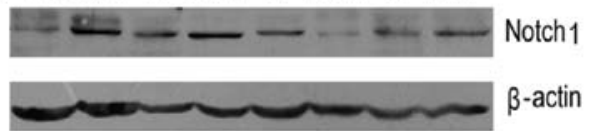

$\mathrm{E}$

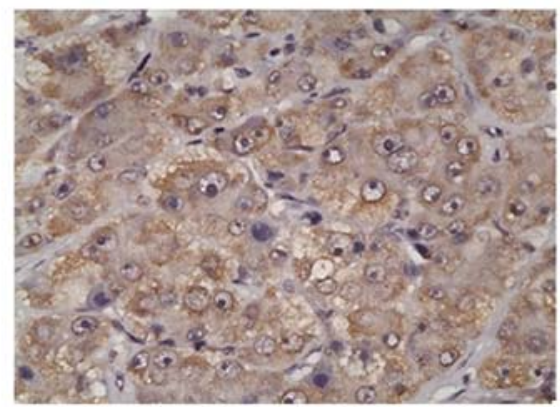

G

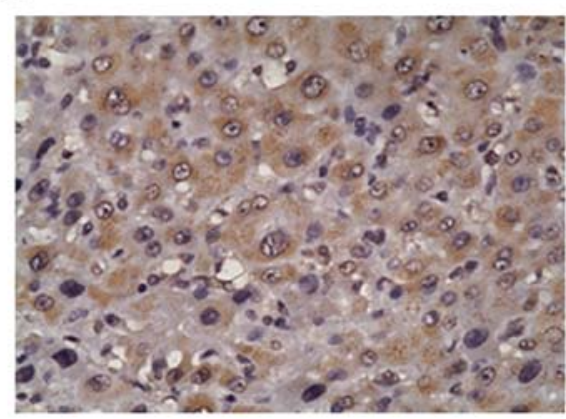

Figure 1. Expression status of Notch1. Loss of Notch1 in TT relative to matched NTT demonstrated by real-time quantitative RT-PCR analysis (A), RT-PCR (B), western blotting (C) and immunohistochemistry (D-G). (D and E) and (F and G) are paired TT and NTT of two patients randomly selected. Positive cells are stained brown. TT, tumor tissue; NTT, non-tumorous tissue.

Table II. Expression of Notch1 in TT and NTT.

\begin{tabular}{lcccr}
\hline & \multicolumn{3}{c}{ Density in TT vs. NTT } & \\
\cline { 2 - 4 } & Normal (n) & Loss (n) & Equal (n) & P-value $^{\text {a }}$ \\
\hline Training cohort (n=206) & 24 & 168 & 14 & $<0.001$ \\
Validation cohort 1 (n=185) & 9 & 84 & 9 & $<0.001$ \\
Validation cohort 2 (n=129) & 22 & 152 & 11 & $<0.001$ \\
& 9 & 62 & 4 & $<0.001$ \\
& 18 & 99 & 92 & $<0.001$ \\
\hline
\end{tabular}

TT, tumor tissue; NTT, non-tumorous tissue. aPaired Wilcoxon test.

Correlation between Notchl status and surgical prognosis in the training cohort. Loss of Notch1 was statistically associated with tumor diameter $(\mathrm{P}=0.036)$ and microvascular invasion (MVI; $\mathrm{P}=0.007$ ) (Table III). Compared with those with loss 
Table III. Notch1 expression and clinicopathological features.

\begin{tabular}{|c|c|c|c|c|c|c|c|}
\hline \multirow[b]{2}{*}{ Variables } & \multicolumn{3}{|c|}{ Training cohort $(n=206)$} & \multirow[b]{2}{*}{ Variables } & \multicolumn{3}{|c|}{ Training cohort $(\mathrm{n}=206)$} \\
\hline & Loss & Normal & P-value & & Loss & Normal & P-value \\
\hline Gender & & & & PLT, $10^{9} / 1$ & & & \\
\hline Female & 7 & 16 & 0.081 & Median & 122 & 117 & $0.439^{\mathrm{a}}$ \\
\hline Male & 91 & 92 & & Range & $20-342$ & 23-302 & \\
\hline Age (years) & & & & PT, sec & & & \\
\hline Median & 50 & 49 & $0.458^{\mathrm{a}}$ & Median & 12.8 & 13.0 & $0.439^{\mathrm{a}}$ \\
\hline Range & $15-72$ & $32-74$ & & Range & $10.0-17.0$ & $9.7-21.1$ & \\
\hline $\mathrm{AFP}, \mu \mathrm{g} / 1$ & & & & GGT, U/l & & & \\
\hline$<20$ & 27 & 37 & 0.299 & Median & 65.7 & 50.5 & $0.033^{\mathrm{a}}$ \\
\hline$\geq 20$ & 71 & 71 & & Range & $10.0-333.0$ & $13.0-391.0$ & \\
\hline HBsAg & & & & ALP, U/l & & & \\
\hline Positive & 79 & 89 & 0.740 & Median & 146 & 126 & $0.031^{\mathrm{a}}$ \\
\hline Negative & 19 & 19 & & Range & $38-553$ & $35-313$ & \\
\hline
\end{tabular}

HBeAg

Positive

Negative

12

0.205

Liver cirrhosis

Yes

No

91

103

0.442

Differentiation

I-II

III-IV

20

78

15

93

Diameter, $\mathrm{cm}$

$\leq 5$

$>5$

41

57

61

47

Encapsulation

Complete

No

MVI

Yes

76

65

43

Tumor no.

Single

Multiple

TNM stage

$$
\text { I }
$$

II

III

ALT, U/1

Median

Range

TBL, $\mu \mathrm{mol} / 1$

$$
\begin{aligned}
& \text { Median } \\
& \text { Range }
\end{aligned}
$$

ALB, g/l

Median

4.0-35.4

11.4

3.0-48.9

Range
42.0

32.4-52.2
AFP, $\alpha$-fetoprotein; HBsAg, hepatitis B surface antigen; $\mathrm{HBeAg}$, hepatitis $\mathrm{B}$ e antigen; MVI, microvascular invasion; ALT, alanine aminotransferase; TBL, total bilirubin; ALB, human serum albumin; PLT, platelets; PT, prothrombin time; GGT, $\gamma$-glutamyl transferase; ALP, alkaline phosphatase; NA, not adopted. ${ }^{a}$ Mann-Whitney test; bisher's exact test.

of Notch1 in TT, patients with normal Notch1 had a prolonged median TTR ( $38.5 \pm 6.1$ vs. $16.0 \pm 3.2$ months, $\mathrm{P}<0.001)$ and an improved 1-, 3- and 5-year survival rates (91, 64 and $49 \%$ vs. 73,31 and $22 \%, \mathrm{P}<0.001$ ) (Fig. 2A and $\mathrm{B}$ ).

Tumor size $\leq 5 \mathrm{~cm}$ in diameter is frequently used in clinical staging systems and therapeutic criteria (24,26-29). We further investigated the patients with tumors $\leq 5 \mathrm{~cm}$ in diameter $(\mathrm{n}=102)$. We also found that patients with normal Notch1 in TT had longer median TTR and higher survival rates (TTR: $53.0 \pm 6.1$ vs. $21.7 \pm 3.5$ months, $\mathrm{P}=0.004$ (Table IV); $1-, 3$ - and 5-year survival rates: 93,71 and $57 \%$ vs. 76,39 and $24 \%$, $\mathrm{P}<0.001$ ) (Fig. 3A and B).

The factors, listed in Table I, showing significance by univariate analysis for prognosis were adopted to multivariate analysis (Table IV). Notch1 status was an independent factor for both recurrence and survival in the cohort, with highest hazard ratio (HR) values among all independent factors (HR, 1.901; 95\% CI, 1.366-2.646; $\mathrm{P}<0.001$ for recurrence; HR, 2.038; 95\% CI, 1.468-2.829; $\mathrm{P}<0.001$ for survival). It was also an independent factor for both recurrence and survival in $\leq 5 \mathrm{~cm}$ subgroup, and had a highest $\mathrm{HR}$ value for survival (HR, 2.337; 95\% CI, 1.431-3.818; $\mathrm{P}=0.001$ ) (Table V).

Validation of the correlation between Notch1 status and surgical prognosis. In the validation cohort 1, normal Notch1 in TT was closely associated with longer median TTR $(39.0 \pm 2.3$ vs. $14.2 \pm 2.2$ months, $\mathrm{P}<0.001$ (Table VI) and higher survival rates (1- and 3-year, 88 and $68 \%$ vs. 66 and $34 \%, \mathrm{P}<0.001$ ) (Fig. $2 \mathrm{C}$ and $\mathrm{D}$ ). In the $\leq 5 \mathrm{~cm}$ subgroup $(\mathrm{n}=75)$, normal Notch1 again predicted a prolonged TTR 
A

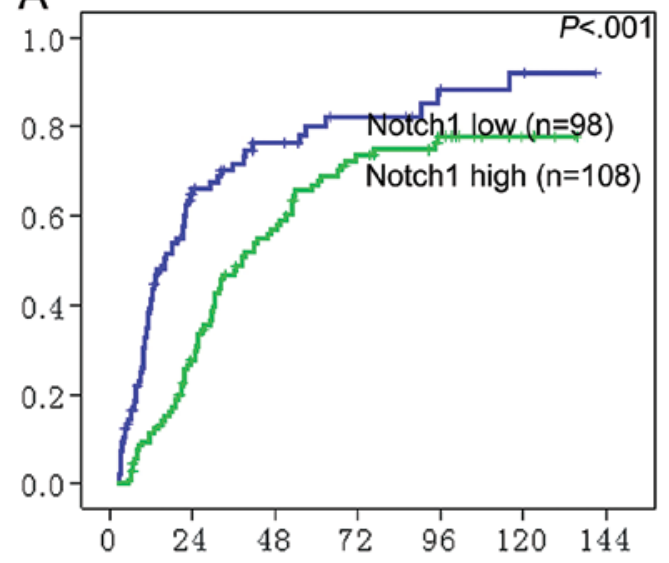

$\begin{array}{lcccccccc}\text { Months } & 0 & 12 & 24 & 36 & 48 & 60 & 72 & 72 \\ \text { Notch1 low patients } & 98 & 55 & 26 & 19 & 14 & 10 & 8 & 5 \\ \text { Cumulative events } & 0 & 38 & 60 & 64 & 67 & 69 & 70 & 73 \\ \text { Notch1 high patients } & 108 & 94 & 73 & 52 & 41 & 30 & 22 & 19 \\ \text { Cumulative events } & 0 & 12 & 29 & 48 & 58 & 67 & 73 & 76\end{array}$

C

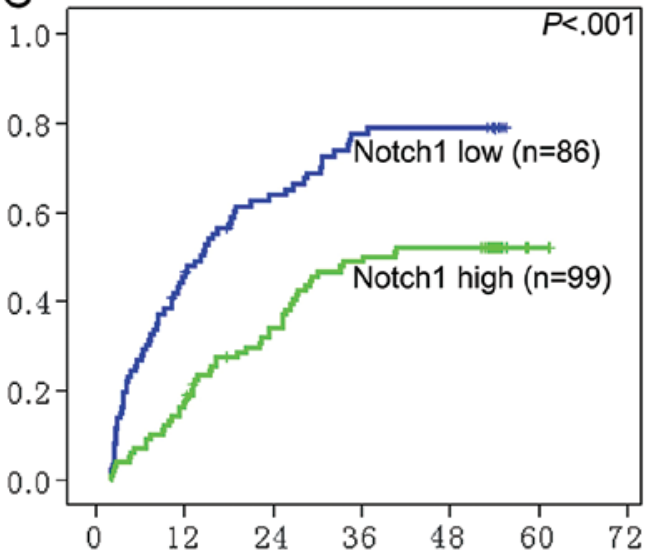

$\begin{array}{llllllll}\text { Months } & 0 & 12 & 24 & 36 & 48 & 60 & 60-\end{array}$

$\begin{array}{lllllllll}\text { Notch1 low patients } & 86 & 62 & 37 & 30 & 27 & 0 & -\end{array}$

$\begin{array}{lllllllll}\text { Cumulative events } & 0 & 24 & 49 & 56 & 59 & 60 & \text { - }\end{array}$

$\begin{array}{llllllll}\text { Notch1 high patients } & 99 & 90 & 73 & 67 & 63 & 2 & 2\end{array}$

$\begin{array}{llllllll}\text { Cumulative events } & 0 & 9 & 25 & 31 & 34 & 34 & 34\end{array}$

$\mathrm{E}$

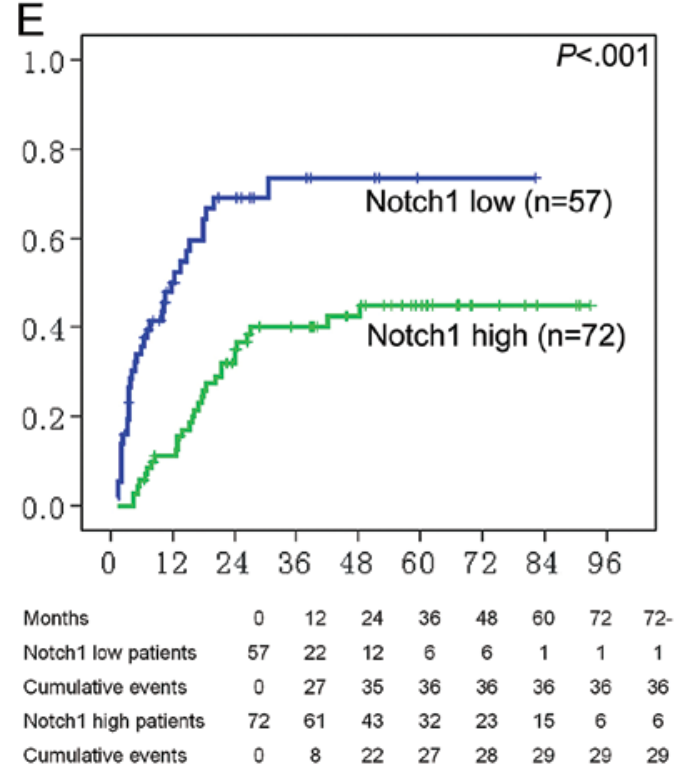

B

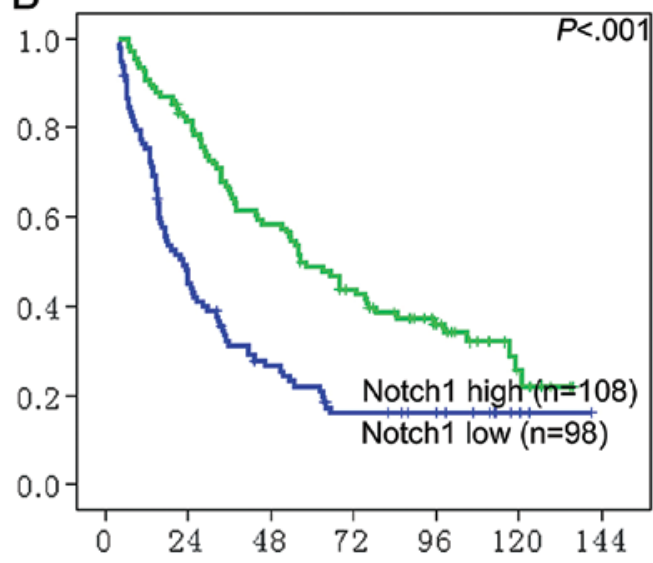

$\begin{array}{lllllllll}\text { Months } & 0 & 12 & 24 & 36 & 48 & 60 & 72 & 72\end{array}$

$\begin{array}{lllllllll}\text { Notch1 low patients } & 98 & 73 & 44 & 28 & 23 & 19 & 13 & 13\end{array}$

$\begin{array}{lllllllll}\text { Cumulative events } & 0 & 24 & 52 & 66 & 70 & 74 & 79 & 79\end{array}$

$\begin{array}{lllllllll}\text { Notch1 high patients } & 108 & 98 & 85 & 69 & 61 & 49 & 42 & 30\end{array}$

$\begin{array}{lllllllll}\text { Cumulative events } & 0 & 10 & 20 & 36 & 44 & 54 & 59 & 71\end{array}$

D

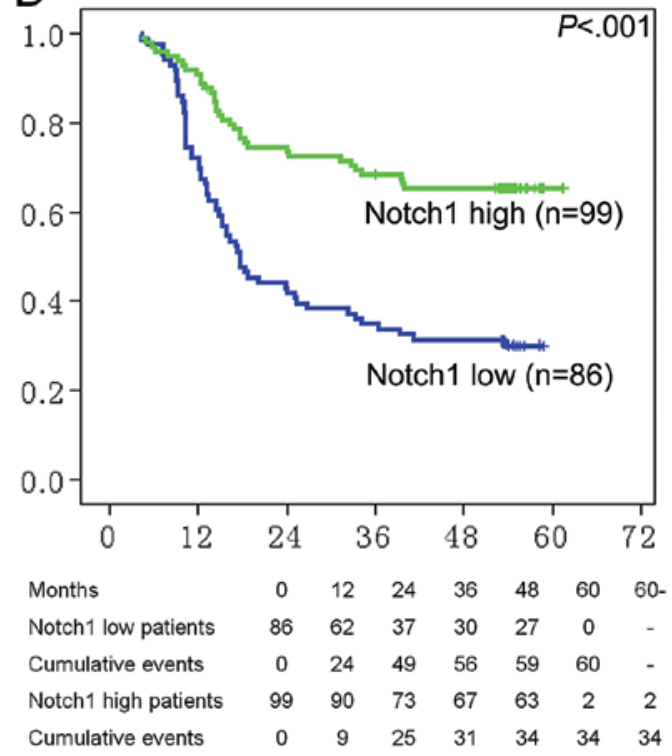

$\mathrm{F}$

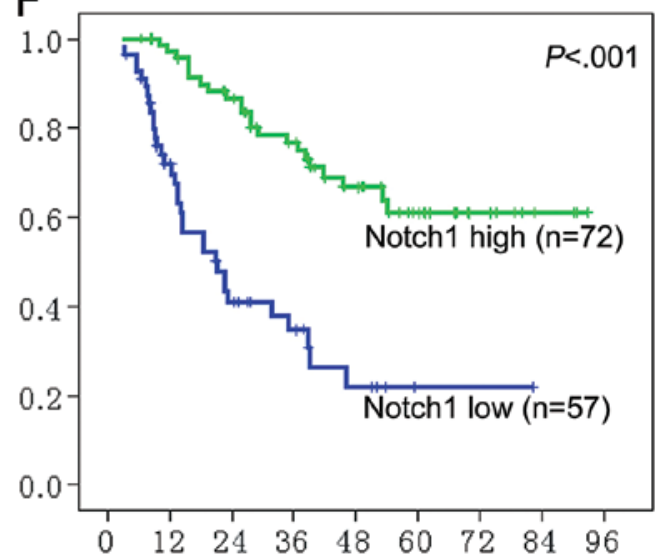

$\begin{array}{lllllllll}\text { Months } & 0 & 12 & 24 & 36 & 48 & 60 & 72 & 72-\end{array}$

$\begin{array}{lllllllll}\text { Notch1 low patients } & 57 & 34 & 18 & 11 & 5 & 1 & 1 & 1\end{array}$

$\begin{array}{lllllllll}\text { Cumulative events } & 0 & 15 & 29 & 31 & 34 & 34 & 34 & 34\end{array}$

$\begin{array}{lllllllll}\text { Notch1 high patients } & 72 & 67 & 56 & 43 & 28 & 17 & 8 & 8\end{array}$

$\begin{array}{lllllllll}\text { Cumulative events } & 0 & 2 & 9 & 15 & 20 & 22 & 22 & 22\end{array}$

Figure 2. Kaplan-Meier analysis of the correlation between Notch1 status and prognosis of early stage HCC patients. Time to recurrence and survival curves of patients in the training cohort $(\mathrm{A}$ and $\mathrm{B})$, validation cohort $1(\mathrm{C}$ and $\mathrm{D})$ and validation cohort $2(\mathrm{E}$ and $\mathrm{F})$. 
A

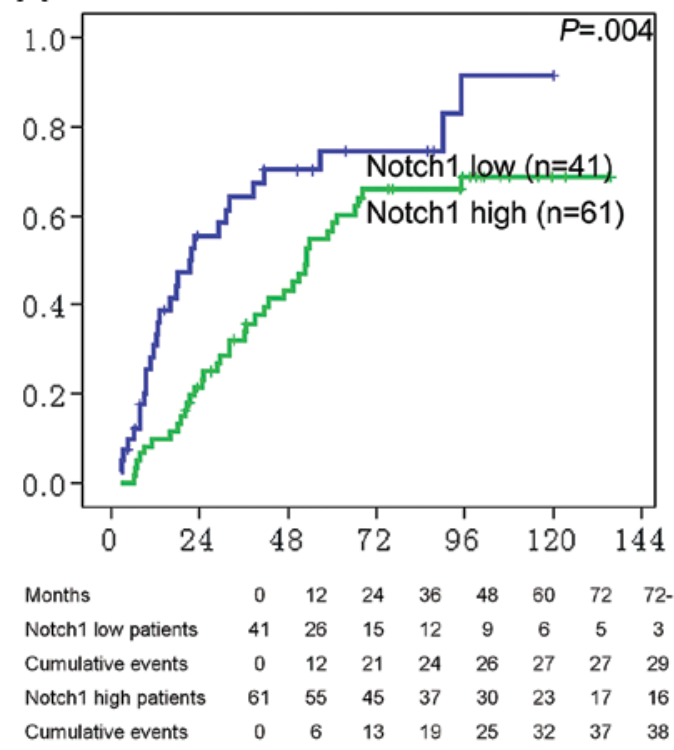

C

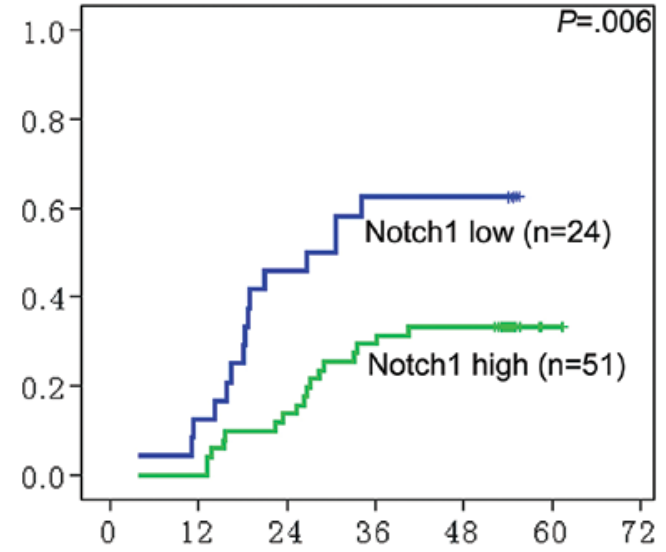

$\begin{array}{llllllll}\text { Months } & 0 & 12 & 24 & 36 & 48 & 60 & 60-\end{array}$ Notch1 low patients $\quad 24 \quad 21 \quad 13 \quad 9 \quad \begin{array}{lllll} & 24 & 0 & -\end{array}$ $\begin{array}{lllllllll}\text { Cumulative events } & 0 & 3 & 11 & 15 & 15 & 15 & -\end{array}$ $\begin{array}{llllllll}\text { Notch1 high patients } & 51 & 51 & 44 & 36 & 34 & 2 & 2\end{array}$ $\begin{array}{llllllll}\text { Cumulative events } & 0 & 0 & 7 & 15 & 17 & 17 & 17\end{array}$

E

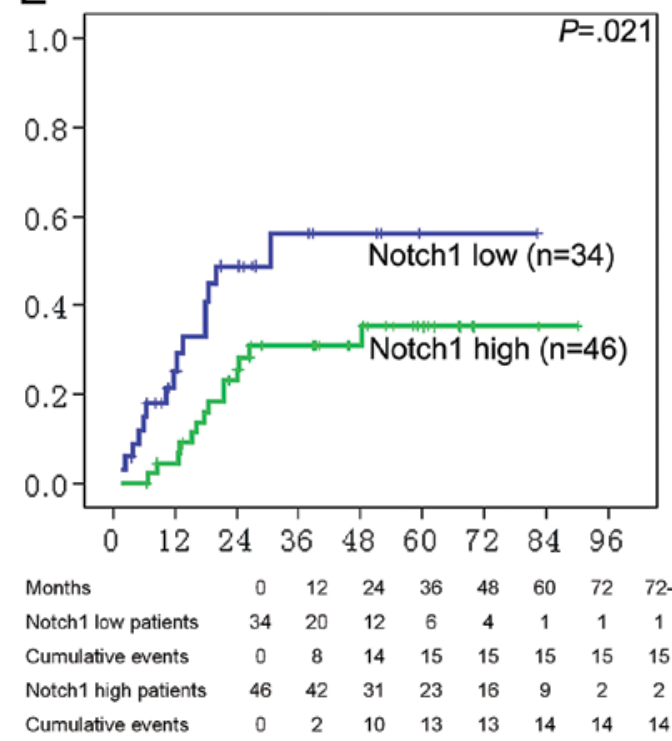

B

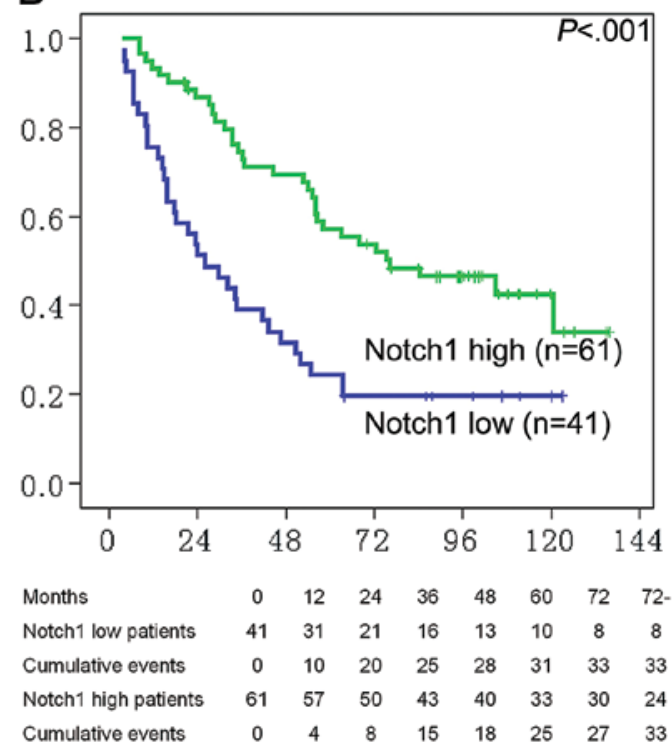

D

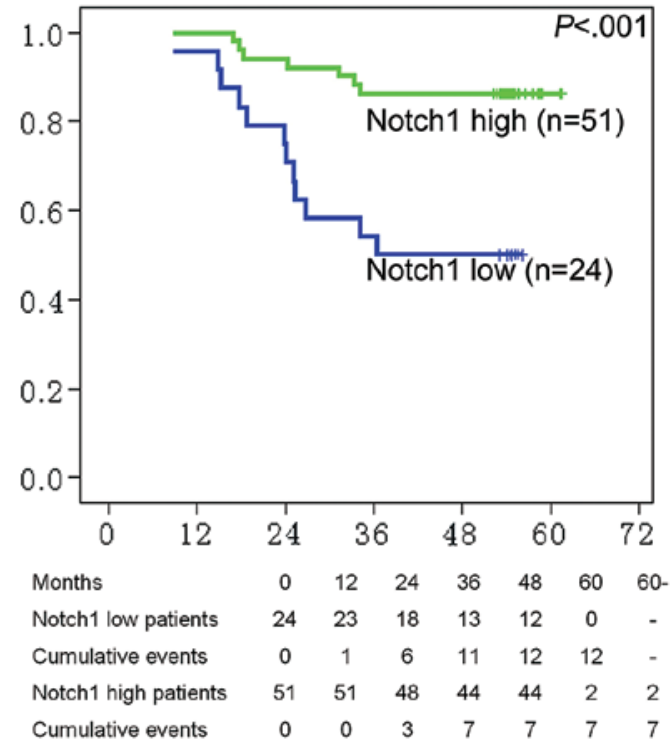

$\mathrm{F}$

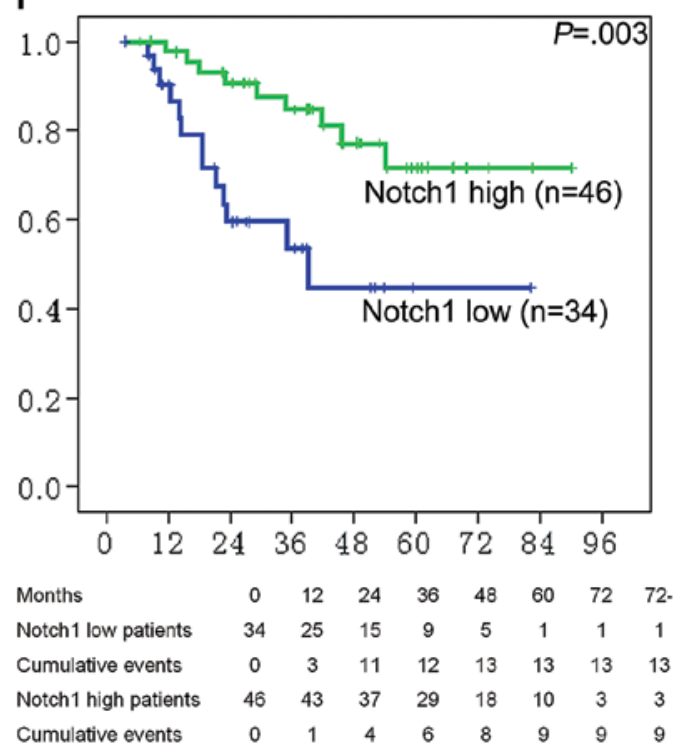

Figure 3. Kaplan-Meier analysis of the correlation between Notch1 expression and prognosis of early stage HCC patients ( $\leq 5 \mathrm{~cm})$. Time to recurrence and survival curves of patients in the training cohort (A and B), validation cohort $1(\mathrm{C}$ and $\mathrm{D})$ and validation cohort 2 (E and F). 
Table IV. Univariate analysis for prognosis in the training cohort.

\begin{tabular}{|c|c|c|c|c|c|}
\hline \multirow[b]{2}{*}{ Variables } & \multirow[b]{2}{*}{$\mathrm{n}$} & \multicolumn{2}{|c|}{ Recurrence (months) } & \multicolumn{2}{|c|}{ Survival (months) } \\
\hline & & Median time to event & $\mathrm{P}$-value & Median time to event & P-value \\
\hline \multicolumn{6}{|c|}{ Training cohort } \\
\hline \multicolumn{6}{|c|}{ Diameter, $\mathrm{cm}$} \\
\hline$\leq 5$ & 102 & $41.5 \pm 8.4$ & \multirow[t]{2}{*}{$<0.001$} & $53.7 \pm 6.0$ & \multirow[t]{2}{*}{0.001} \\
\hline$>5$ & 104 & $21.7 \pm 1.9$ & & $27.9 \pm 3.7$ & \\
\hline \multicolumn{6}{|c|}{ Encapsulation } \\
\hline Complete & 60 & $46.7 \pm 9.2$ & \multirow[t]{2}{*}{0.011} & $62.1 \pm 7.4$ & \multirow[t]{2}{*}{0.001} \\
\hline No & 146 & $22.6 \pm 2.3$ & & $30.1 \pm 3.8$ & \\
\hline \multicolumn{6}{|l|}{ Transfusion } \\
\hline Yes & 70 & $21.3 \pm 3.1$ & \multirow[t]{2}{*}{0.074} & $28.8 \pm 5.5$ & \multirow[t]{2}{*}{0.029} \\
\hline No & 136 & $31.3 \pm 3.9$ & & $44.3 \pm 7.5$ & \\
\hline \multicolumn{6}{|l|}{ Tumor no. } \\
\hline Single & 154 & $32.1 \pm 3.6$ & \multirow[t]{2}{*}{0.001} & $51.3 \pm 7.2$ & \multirow[t]{2}{*}{0.001} \\
\hline Multiple & 52 & $14.0 \pm 2.7$ & & $24.0 \pm 4.0$ & \\
\hline \multicolumn{6}{|l|}{$\mathrm{AFP}, \mu \mathrm{g} / \mathrm{l}$} \\
\hline$<20$ & 64 & $41.7 \pm 10.0$ & \multirow[t]{2}{*}{0.026} & $58.2 \pm 5.9$ & \multirow[t]{2}{*}{0.051} \\
\hline$\geq 20$ & 142 & $21.9 \pm 3.0$ & & $30.1 \pm 3.6$ & \\
\hline \multicolumn{6}{|l|}{ MVI } \\
\hline Yes & 141 & $23.4 \pm 3.3$ & \multirow[t]{2}{*}{0.031} & $32.9 \pm 3.2$ & \multirow[t]{2}{*}{0.095} \\
\hline No & 65 & $38.4 \pm 9.1$ & & $55.3 \pm 6.1$ & \\
\hline \multicolumn{6}{|c|}{ Notch1 in TT } \\
\hline Loss & 98 & $16.0 \pm 3.2$ & \multirow[t]{2}{*}{$<0.001$} & $22.6 \pm 3.1$ & \multirow[t]{2}{*}{$<0.001$} \\
\hline Normal & 108 & $38.5 \pm 6.1$ & & $56.6 \pm 6.6$ & \\
\hline \multicolumn{6}{|c|}{$\leq 5 \mathrm{~cm}$ subgroup } \\
\hline \multicolumn{6}{|l|}{ HBsAg } \\
\hline Positive & 83 & $32.2 \pm 4.8$ & 0.008 & $46.5 \pm 8.7$ & 0.128 \\
\hline Negative & 19 & $86.7 \pm 10.1$ & & $105.1 \pm 35.1$ & \\
\hline Tumor no. & & & & & \\
\hline Single & 79 & $46.7 \pm 7.0$ & 0.125 & $63.0 \pm 8.3$ & 0.002 \\
\hline Multiple & 23 & $8.0 \pm 3.8$ & & $24.0 \pm 9.4$ & \\
\hline Encapsulati & & & & & \\
\hline Complete & 36 & $53.0 \pm 9.1$ & 0.243 & $105.1 \pm 38.3$ & 0.032 \\
\hline No & 66 & $36.2 \pm 4.0$ & & $44.3 \pm 11.2$ & \\
\hline Notch1 in $\mathrm{T}$ & & & & & \\
\hline Loss & 41 & $21.7 \pm 3.5$ & 0.004 & $25.8 \pm 6.9$ & $<0.001$ \\
\hline Normal & 61 & $53.0 \pm 6.1$ & & $76.3 \pm 21.5$ & \\
\hline
\end{tabular}

AFP, $\alpha$-fetoprotein; MVI, microvascular invasion; HBsAg, hepatitis B surface antigen; TT, tumor tissue.

(49.3 \pm 2.5 vs. $26.7 \pm 7.2$ months, $\mathrm{P}=0.006)$ and improved survival rates (1- and 3-year, 100 and $86 \%$ vs. 96 and $50 \%$, $\mathrm{P}<0.001$ ) (Fig. 3C and D).

Normal Notch1 in TT also predicted a better prognosis in the validation cohort 2 (TTR, $59.6 \pm 4.7$ vs. $11.9 \pm 2.4$ months, $\mathrm{P}<0.001$; 1-, 3- and 5-year survival rates, 97,75 and $61 \%$ vs. 68 , 35 and $22 \%, \mathrm{P}<0.001$, Fig. $2 \mathrm{E}$ and $\mathrm{F}$ ) and the $\leq 5 \mathrm{~cm}$ subgroup $(\mathrm{n}=80$, TTR, $65.9 \pm 5.3$ vs. $30.6 \pm 11.4$ months, $\mathrm{P}=0.021 ; 1-$, 3 - and 5-year survival rates, 98, 85 and $71 \%$ vs. 86,54 and $45 \%$, $\mathrm{P}=0.003$ ) (Fig. 3E and F).
The univariate analysis (Tables VI and VII) and multivariate analysis (Table V) indicated again that the Notch1 status was an independent factor for recurrence and survival in the validation cohorts and their $\leq 5 \mathrm{~cm}$ subgroups. The HR value of Notch1 status ranked in the forefront among all independent factors for both recurrence and survival in the validation cohort 1 (HR, 2.056; 95\% CI, 1.409-3.000; $\mathrm{P}<0.001$ for recurrence; $\mathrm{HR}, 2.381$; $95 \% \mathrm{CI}, 1.551-3.656$; $\mathrm{P}<0.001$ for survival), and was the highest for both prognostic indexes in the validation cohort 2 (HR, 4.341; 95\% CI, 2.517-7.487; 
Table V. Multivariate analysis and hazard ratios for recurrence and survival.

\begin{tabular}{|c|c|c|c|c|c|}
\hline & \multirow[b]{2}{*}{ Variables } & \multicolumn{2}{|c|}{ Time to recurrence } & \multicolumn{2}{|c|}{ Overall survival } \\
\hline & & $\mathrm{HR}(95 \% \mathrm{CI})$ & P-value & $\mathrm{HR}(95 \% \mathrm{CI})$ & P-value \\
\hline \multicolumn{6}{|l|}{ Cohorts } \\
\hline \multirow[t]{4}{*}{ Training cohort } & Diameter: $>5$ vs. $\leq 5 \mathrm{~cm}$ & $1.674(1.204-2.328)$ & 0.002 & $1.487(1.071-2.065)$ & 0.018 \\
\hline & Tumor no.: multiple vs. single & $1.709(1.195-2.443)$ & 0.003 & $1.629(1.140-2.327)$ & 0.007 \\
\hline & Encapsulation: no vs. complete & $1.644(1.144-2.363)$ & 0.007 & $1.886(1.292-2.751)$ & 0.001 \\
\hline & Notch1 in TT: loss vs. normal & $1.901(1.366-2.646)$ & $<0.001$ & $2.038(1.468-2.829)$ & $<0.001$ \\
\hline \multirow[t]{4}{*}{ Validation cohort 1} & Diameter: $>5$ vs. $\leq 5 \mathrm{~cm}$ & $2.418(1.580-3.701)$ & $<0.001$ & $2.932(1.742-4.934)$ & $<0.001$ \\
\hline & Transfusion: yes vs. no & $2.147(1.396-3.301)$ & $<0.001$ & $1.965(1.245-3.103)$ & 0.004 \\
\hline & Encapsulation: no vs. complete & $2.200(1.314-3.684)$ & 0.003 & $3.020(1.551-5.878)$ & 0.001 \\
\hline & Notch1 in TT: loss vs. normal & $2.056(1.409-3.000)$ & $<0.001$ & $2.381(1.551-3.656)$ & $<0.001$ \\
\hline \multirow[t]{3}{*}{ Validation cohort 2} & Diameter: $>5$ vs. $\leq 5 \mathrm{~cm}$ & $4.269(2.495-7.303)$ & $<0.001$ & $4.111(2.379-7.106)$ & $<0.001$ \\
\hline & Tumor no.: multiple vs. single & $2.003(1.206-3.325)$ & 0.007 & $2.161(1.262-3.703)$ & 0.005 \\
\hline & Notch1 in TT: loss vs. normal & $4.341(2.517-7.487)$ & $<0.001$ & $4.721(2.680-8.315)$ & $<0.001$ \\
\hline \multicolumn{6}{|l|}{$\leq 5 \mathrm{~cm}$ subgroups } \\
\hline \multirow[t]{3}{*}{ Training cohort } & HBsAg: positive vs. negative & $2.815(1.332-5.946)$ & 0.007 & & NA \\
\hline & Tumor no.: multiple vs. single & & NA & $2.134(1.243-3.664)$ & 0.006 \\
\hline & Notch1 in TT: loss vs. normal & $2.154(1.317-3.524)$ & 0.002 & $2.337(1.431-3.818)$ & 0.001 \\
\hline \multirow[t]{2}{*}{ Validation cohort 1} & MVI: yes vs. no & $2.163(1.080-4.331)$ & 0.030 & $2.721(1.093-6.776)$ & 0.032 \\
\hline & Notch1 in TT: loss vs. normal & $2.514(1.251-5.049)$ & 0.010 & $4.621(1.814-11.773)$ & 0.001 \\
\hline \multirow[t]{2}{*}{ Validation cohort 2} & Tumor no.: multiple vs. single & $3.269(1.556-6.866)$ & 0.002 & & NA \\
\hline & Notch1 in TT: loss vs. normal & $2.599(1.236-5.466)$ & 0.012 & $3.496(1.469-8.322)$ & 0.005 \\
\hline
\end{tabular}

HBsAg, hepatitis B surface antigen; MVI, microvascular invasion; NA, not adopted; TT, tumor tissue; CI, confidence interval.

$\mathrm{P}<0.001$ for recurrence; HR, 4.721; 95\% CI, 2.680-8.315; $\mathrm{P}<0.001$ for survival). The similar results were obtained in the $\leq 5 \mathrm{~cm}$ subgroups (Table V). The prognostic value of Notch1 in the training cohort was fully confirmed by the validation studies.

Correlation between Notch1 status and early tumor recurrence. It was reported that the recurrence of $\mathrm{HCC}$ within and after postoperative two years has different molecular background (12). In the training cohort, patients with loss of Notch1 had an increased incidence of early recurrence, compared with those with high Notch1 expression (61.2 vs. 26.9\%, $\mathrm{P}<0.001)$. Additionally, Notch1 status was also an independent factor for early recurrence with the highest $\mathrm{HR}$ value (HR, 3.228; 95\% CI, 2.059-5.062; $\mathrm{P}<0.001)$. These results could be verified by the analysis of the validation cohorts (Table VIII).

The similar results were obtained in the $\leq 5 \mathrm{~cm}$ subgroups (2-year recurrence rate, 51.2 vs. $21.3 \%, \mathrm{P}=0.002 ; 45.8$ vs. $13.7 \%, \mathrm{P}=0.002 ; 41.2$ vs. $21.7 \%, \mathrm{P}=0.014$ in the subgroup of the training cohort, validation cohort 1 and 2, respectively). Notch1 status was also an independent factor for early recurrence (Table VIII).

\section{Discussion}

The present study, for the first time, investigated the relationship between Notch1 status and outcome of early stage
HCC patients undergoing hepatectomy. We found that loss of Notch1 was often observed in HCC, and early HCC with loss Notch1 was more likely to exhibit a malignant phenotype and presented a worse surgical prognosis.

Previous studies indicated that Notch1 is involved in carcinogenesis in some types of malignancies $(17,30)$. It was reported that the function of Notch1 in malignancy depended on the different target gene(s) or downstream pathway(s) it turned on/off $(31,32)$. Weng et al found that c-myc as a developmentally regulated direct downstream target of Notch1 contributed to the growth of $\mathrm{T}$ acute lymphoblastic leukemia/lymphoma (31), in contrast, in another study which described Notch1 binding to P21, a decrease in keratinocyte proliferation and a delay in terminal differentiation was observed (32). The function of Notch1 was also affected by the interplay between Notch1 and other signaling pathways such as Wnt and Ras (33). The authors reported that in Notch1deficient mice bearing basal cell carcinomas, Wnt signaling seemed to be abnormal as they showed an increase in both levels of $\beta$-catenin and activity of LEF-1. Notch1-deficient mice were also more susceptible to skin tumor development in the context of Ras activation or carcinogen exposure (33). These studies suggested that activation of the Notch1 pathway may display an inhibitory function in carcinogenesis of the malignancy.

Notch1 may also play an important role in hepatic carcinogenesis, and activation of Notch1 signaling suppressed 
Table VI. Univariate analysis for prognosis in the validation cohort 1.

\begin{tabular}{|c|c|c|c|c|c|}
\hline \multirow[b]{2}{*}{ Variables } & \multirow[b]{2}{*}{ No. } & \multicolumn{2}{|c|}{ Recurrence (months) } & \multicolumn{2}{|c|}{ Survival (months) } \\
\hline & & Median time to event & P-value & Median time to event & P-value \\
\hline \multicolumn{6}{|c|}{ Validation cohort 1} \\
\hline \multicolumn{6}{|l|}{$\mathrm{AFP}, \mu \mathrm{g} / 1$} \\
\hline$<20$ & 57 & $38.8 \pm 3.1$ & 0.009 & $45.0 \pm 2.8$ & 0.015 \\
\hline$\geq 20$ & 128 & $21.0 \pm 4.2$ & & $33.3 \pm 8.5$ & \\
\hline \multicolumn{6}{|c|}{ Encapsulation } \\
\hline Complete & 43 & $45.5 \pm 3.0$ & $<0.001$ & $52.7 \pm 2.5$ & $<0.001$ \\
\hline No & 142 & $18.3 \pm 3.0$ & & $24.2 \pm 5.6$ & \\
\hline \multicolumn{6}{|l|}{ MVI } \\
\hline Yes & 99 & $16.2 \pm 4.1$ & 0.001 & $24.2 \pm 7.3$ & 0.001 \\
\hline No & 86 & $37.7 \pm 2.6$ & & $44.4 \pm 2.4$ & \\
\hline \multicolumn{6}{|l|}{ Tumor no. } \\
\hline Single & 152 & $27.1 \pm 2.6$ & 0.007 & $41.2 \pm 1.9$ & 0.058 \\
\hline Multiple & 33 & $11.4 \pm 3.5$ & & $14.8 \pm 2.9$ & \\
\hline \multicolumn{6}{|c|}{ Diameter, $\mathrm{cm}$} \\
\hline$\leq 5$ & 75 & $44.8 \pm 2.3$ & $<0.001$ & $51.9 \pm 2.0$ & $<0.001$ \\
\hline$>5$ & 110 & $12.2 \pm 1.8$ & & $15.9 \pm 1.4$ & \\
\hline \multicolumn{6}{|c|}{ Notch1 in TT } \\
\hline Loss & 86 & $14.2 \pm 2.2$ & $<0.001$ & $17.8 \pm 2.0$ & $<0.001$ \\
\hline Normal & 99 & $39.0 \pm 2.3$ & & $46.5 \pm 2.2$ & \\
\hline \multicolumn{6}{|l|}{ Transfusion } \\
\hline Yes & 38 & $10.4 \pm 2.4$ & $<0.001$ & $14.9 \pm 2.4$ & $<0.001$ \\
\hline No & 147 & $28.6 \pm 3.0$ & & $41.7 \pm 1.9$ & \\
\hline \multicolumn{6}{|c|}{$\leq 5 \mathrm{~cm}$ subgroup } \\
\hline \multicolumn{6}{|l|}{ MVI } \\
\hline Yes & 28 & $28.3 \pm 7.2$ & 0.020 & $44.1 \pm 3.5$ & 0.023 \\
\hline No & 47 & $49.1 \pm 2.6$ & & $55.4 \pm 2.0$ & \\
\hline \multicolumn{6}{|c|}{ Notch1 in TT } \\
\hline Loss & 24 & $26.7 \pm 7.2$ & 0.006 & $39.4 \pm 3.6$ & $<0.001$ \\
\hline Normal & 51 & $49.3 \pm 2.5$ & & $56.5 \pm 1.8$ & \\
\hline
\end{tabular}

AFP, $\alpha$-fetoprotein; MVI, microvascular invasion; TT, tumor tissue.

HCC cell proliferation (20-22,34). The function of Notch1 in HCC seems to be closely associated with HBV infection. A recent study revealed that $\mathrm{HBx}$ overexpression in the Huh7 cell line decreased the endogenous protein level of the intracellular domain of Notch1, and mRNA levels of its downstream target genes through suppressing presenilin1 transcription. This process enhanced cell proliferation, induced G1-S cell cycle progression and blunted cellular senescence in vitro and in vivo (22). Indeed, in the present study, the majority of patients $(513 / 520,98.7 \%)$ undergoing the clinical observation had a background of HBV infection. Our results revealed that Notch1 expression was significantly decreased in HCC and that lower expression of this molecule was associated with certain invasive pathological features and was an independent and powerful risk factor for poor prognosis (Table V). These observations suggest that normal Notch1 in TT is a protective factor, a notion that is supported by previous findings that Notch1 acts as a tumor suppressor gene in HCC (20-22).

Hepatectomy is recommended for HCC patients at early stage such as BCLC stage 0 and A $(7,8,35)$. However, some early stage HCC patients also have a poor prognosis. It has become increasingly more important that biological prognostic predictors for early HCC should be found, as the number of patients with early $\mathrm{HCC}$ who are receiving surgical treatment is rising $(7,8,25)$. There were several molecular markers which were also found to be associated with the prognosis of $\leq 5 \mathrm{~cm}$ HCC $(36,37)$, however, an ideal one that has strong correlations with clinical outcomes and that is easy to measure is still lacking. Our results indicated that Notch1 status in TT is closely associated with tumor recurrence and survival in patients at BCLC stage 0/A. Patients with normal Notch1 have a longer TTR and survival compared with those with low 
Table VII. Univariate analysis for prognosis in the validation cohort 2.

\begin{tabular}{|c|c|c|c|c|c|}
\hline \multirow[b]{2}{*}{ Variables } & \multirow[b]{2}{*}{ No. } & \multicolumn{2}{|c|}{ Recurrence (months) } & \multicolumn{2}{|c|}{ Survival (months) } \\
\hline & & Median time to event & P-value & Median time to event & P-value \\
\hline \multicolumn{6}{|c|}{ Validation cohort 2} \\
\hline \multicolumn{6}{|l|}{ MVI } \\
\hline Yes & 56 & $18.6 \pm 5.5$ & \multirow[t]{2}{*}{0.044} & $29.1 \pm 7.6$ & \multirow[t]{2}{*}{0.006} \\
\hline No & 73 & $53.6 \pm 5.2$ & & $63.4 \pm 5.0$ & \\
\hline \multicolumn{6}{|l|}{ Tumor no. } \\
\hline Single & 80 & $58.8 \pm 4.8$ & \multirow{2}{*}{$<0.001$} & $63.7 \pm 4.5$ & \multirow[t]{2}{*}{0.001} \\
\hline Multiple & 49 & $15.3 \pm 2.8$ & & $25.9 \pm 5.7$ & \\
\hline \multicolumn{6}{|c|}{ Diameter, $\mathrm{cm}$} \\
\hline$\leq 5$ & 80 & $58.7 \pm 4.5$ & \multirow{2}{*}{$<0.001$} & $66.0 \pm 4.2$ & \multirow{2}{*}{$<0.001$} \\
\hline$>5$ & 49 & $9.9 \pm 3.6$ & & $25.9 \pm 6.4$ & \\
\hline \multicolumn{6}{|c|}{ Notch1 in TT } \\
\hline Loss & 57 & $11.9 \pm 2.4$ & \multirow[t]{2}{*}{$<0.001$} & $21.1 \pm 4.2$ & \multirow[t]{2}{*}{$<0.001$} \\
\hline Normal & 72 & $59.6 \pm 4.7$ & & $68.8 \pm 4.2$ & \\
\hline \multicolumn{6}{|c|}{ Transfusion } \\
\hline Yes & 19 & $9.9 \pm 4.4$ & \multirow[t]{2}{*}{$<0.001$} & $15.6 \pm 6.5$ & \multirow[t]{2}{*}{$<0.001$} \\
\hline No & 110 & $52.9 \pm 4.1$ & & $60.8 \pm 3.9$ & \\
\hline \multicolumn{6}{|c|}{$\leq 5 \mathrm{~cm}$ subgroup } \\
\hline \multicolumn{6}{|c|}{ Tumor no. } \\
\hline Single & 53 & $68.4 \pm 5.1$ & \multirow[t]{2}{*}{0.002} & $69.6 \pm 5.0$ & \multirow[t]{2}{*}{0.224} \\
\hline Multiple & 27 & $19.9 \pm 5.2$ & & $54.5 \pm 6.8$ & \\
\hline \multicolumn{6}{|c|}{ Notch1 in TT } \\
\hline Loss & 34 & $30.6 \pm 11.4$ & \multirow[t]{2}{*}{0.021} & $39.0 \pm 12.6$ & \multirow[t]{2}{*}{0.003} \\
\hline Normal & 46 & $65.9 \pm 5.3$ & & $74.4 \pm 4.6$ & \\
\hline
\end{tabular}

Table VIII. Multivariate analysis and hazard ratios for early tumor recurrence.

\begin{tabular}{llrr}
\hline Cohorts & \multicolumn{1}{c}{ Variables } & HR $(95 \%$ CI $)$ & P-value \\
\hline Cohorts & & & \\
Training cohort & Diameter: $>5$ vs. $\leq 5 \mathrm{~cm}$ & $1.553(1.007-2.394)$ & 0.046 \\
& Tumor no.: multiple vs. single & $2.521(1.637-3.882)$ & $<0.001$ \\
& Encapsulation: no vs. complete & $1.940(1.163-3.238)$ & 0.011 \\
& Notch1 in TT: loss vs. normal & $3.228(2.059-5.062)$ & $<0.001$ \\
Validation cohort 1 & Diameter: $>5$ vs. $\leq 5$ cm & $2.828(1.658-4.821)$ & $<0.001$ \\
& Transfusion: yes vs. no & $2.292(1.424-3.689)$ & 0.001 \\
& Encapsulation: no vs. complete & $3.736(1.781-7.837)$ & $<0.001$ \\
Validation cohort 2 & Notch1 in TT: loss vs. normal & $2.446(1.570-3.810)$ & $<0.001$ \\
& Diameter: $>5$ vs. $\leq 5$ cm & $4.707(2.637-8.402)$ & $<0.001$ \\
& Tumor no.: multiple vs. single & $1.791(1.041-3.083)$ & 0.035 \\
$\leq 5$ cm subgroups & Notch1 in TT: loss vs. normal & $5.071(2.823-9.110)$ & $<0.001$ \\
Training cohort & & & 0.007 \\
Validation cohort 1 & HBsAg: positive vs. negative & $4.952(1.184-20.713)$ & 0.002 \\
& Notch1 in TT: loss vs. normal & $3.639(1.812-7.308)$ & 0.016 \\
Validation cohort 2 & MVI: yes vs. no & $3.215(1.244-8.309)$ & 0.004 \\
& Notch1 in TT: loss vs. normal & $4.032(1.557-10.436)$ & 0.002 \\
& Tumor no.: multiple vs. single & $3.544(1.562-8.042)$ & 0.007
\end{tabular}


Notch1 expression, a observation made in a retrospective study and validated by a prospective cohort from the same medical center, and also verified in an independent cohort from another center. Furthermore, the HR value of Notch1 status for recurrence and survival from multivariate analyses was either higher or highest among all independent factors.

Considering that HCC patients at BCLC stage 0 and $\leq 5 \mathrm{~cm}$ stage A are usually thought to be optimal candidates for surgical resection $(24,26,29)$, we therefore evaluated the prognostic values of this molecule in these patients. The Notch1 status was also statistically associated with TTR and survival in three subgroups, and was unexclusively an independent factor for both prognostic indexes, with higher or highest HR values for prognosis (Table V). In addition, the prognostic role of the Notch1 status in the $\leq 5 \mathrm{~cm}$ subgroup seemed to be more important than that in the whole cohort, as fewer independent prognostic factors were found in all three $\leq 5 \mathrm{~cm}$ subgroups. Therefore, the earlier the HCC stage the more difficult the prognostic prediction; thus, the predictive value of Notch1 status in early HCC should be fully assessed.

The present study also suggests that tumors with loss of Notch1 tend to undergo early relapse after surgery, as the 2-year recurrence rate was higher in the patients with loss of Notch1 relative to those with normal Notch1 in all three cohorts and their $\leq 5 \mathrm{~cm}$ subgroups (Figs. 2 and 3). It has been reported that HCC recurrence within two years after surgery is closely associated with molecular features of the primary tumor, but that the recurrence after postoperative two years appears to result from new primary tumors arising in a damaged liver (12). Our results suggest that loss of Notch1, which was associated with invasive features such as larger tumor diameter and higher incidence of vascular invasion, may contribute to early tumor recurrence. While there is a lack of mechanistic understanding regarding these issues in $\mathrm{HCC}$, studies on breast cancer indicate that aberrant expression of this molecule can promote tumor growth and metastasis, which was characterized by inhibition of anoikis and induction of epithelial-to-mesenchymal transition (38). Our results thus suggest that Notch1 status may have meaningful prognostic discrimination for early postoperative recurrence of HCC after hepatectomy.

In conclusion, our results suggest that loss of Notch1 in HCC may be an informative warning sign that these early HCC patients should receive more intensive monitoring and appropriate adjuvant therapies. Further studies are needed to establish whether Notch1 has full potential as a new therapeutic target in liver cancer.

\section{Acknowledgements}

We thank Dr Jian Lu for statistical assistance, Dr Li Gao for the pathological examinations, Dr Anita S.F. Chong and Dr Yi-Zheng Wang for critical reading of the manuscript. The present study was supported by a grant from the State Key Project on Infectious Diseases of China (no. 2008ZX10002025,019,2012ZX10002-016 to F.S.), grants from National Natural Science Foundation of China (no. 30772141 to F.S and no. 81071867 to W.K.), a grant from the Science Fund for Creative Research Groups, and a grant of the Shanghai Hospital Development Program (SHDC12010121 to F.S.).

\section{References}

1. Bosch FX, Ribes J, Díaz M and Cléries R: Primary liver cancer: Worldwide incidence and trends. Gastroenterology 127 (Suppl 1): S5-S16, 2004.

2. Yang L, Parkin DM, Whelan S, Zhang S, Chen Y, Lu F and Li L: Statistics on cancer in China: Cancer registration in 2002. Eur J Cancer Prev 14: 329-335, 2005.

3. Portolani N, Coniglio A, Ghidoni S, Giovanelli M, Benetti A, Tiberio GA and Giulini SM: Early and late recurrence after liver resection for hepatocellular carcinoma: Prognostic and therapeutic implications. Ann Surg 243: 229-235, 2006.

4. Bruix J, Boix L, Sala M and Llovet JM: Focus on hepatocellular carcinoma. Cancer Cell 5: 215-219, 2004.

5. Poon RT, Fan ST, Lo CM, Liu CL and Wong J: Intrahepatic recurrence after curative resection of hepatocellular carcinoma: Long-term results of treatment and prognostic factors. Ann Surg 229: 216-222, 1999.

6. Shimozawa $\mathrm{N}$ and Hanazaki K: Longterm prognosis after hepatic resection for small hepatocellular carcinoma. J Am Coll Surg 198: 356-365, 2004.

7. Bruix J and Sherman M; Practice Guidelines Committee, American Association for the Study of Liver Diseases: Management of hepatocellular carcinoma. Hepatology 42: 1208-1236, 2005.

8. Llovet JM, Brú C and Bruix J: Prognosis of hepatocellular carcinoma: The BCLC staging classification. Semin Liver Dis 19: 329-338, 1999.

9. Llovet JM and Bruix J: Novel advancements in the management of hepatocellular carcinoma in 2008. J Hepatol 48 (Suppl 1): S20-S37, 2008.

10. Izumi R, Shimizu K, Ii T, Yagi M, Matsui O, Nonomura A and Miyazaki I: Prognostic factors of hepatocellular carcinoma in patients undergoing hepatic resection. Gastroenterology 106: 720-727, 1994.

11. Iizuka N, Oka M, Yamada-Okabe H, Nishida M, Maeda Y, Mori N, Takao T, Tamesa T, Tangoku A, Tabuchi H, et al: Oligonucleotide microarray for prediction of early intrahepatic recurrence of hepatocellular carcinoma after curative resection. Lancet 361: 923-929, 2003.

12. Hoshida Y, Villanueva A, Kobayashi M, Peix J, Chiang DY, Camargo A, Gupta S, Moore J, Wrobel MJ, Lerner J, et al: Gene expression in fixed tissues and outcome in hepatocellular carcinoma. N Engl J Med 359: 1995-2004, 2008.

13. Greenwald I: LIN-12/Notch signaling: Lessons from worms and flies. Genes Dev 12: 1751-1762, 1998.

14. Sestan N, Artavanis-Tsakonas S and Rakic P: Contact-dependent inhibition of cortical neurite growth mediated by notch signaling. Science 286: 741-746, 1999.

15. Dontu G, Jackson KW, McNicholas E, Kawamura MJ, Abdallah WM and Wicha MS: Role of Notch signaling in cell-fate determination of human mammary stem/progenitor cells. Breast Cancer Res 6: R605-R615, 2004.

16. Ellisen LW, Bird J, West DC, Soreng AL, Reynolds TC, Smith SD and Sklar J: TAN-1, the human homolog of the Drosophila Notch gene, is broken by chromosomal translocations in T lymphoblastic neoplasms. Cell 66: 649-661, 1991.

17. Weng AP and Aster JC: Multiple niches for Notch in cancer: Context is everything. Curr Opin Genet Dev 14: 48-54, 2004.

18. Fan X, Matsui W, Khaki L, Stearns D, Chun J, Li YM and Eberhart CG: Notch pathway inhibition depletes stem-like cells and blocks engraftment in embryonal brain tumors. Cancer Res 66: 7445-7452, 2006.

19. Dufraine J, Funahashi Y and Kitajewski J: Notch signaling regulates tumor angiogenesis by diverse mechanisms. Oncogene 27: 5132-5137, 2008.

20. Qi R, An H, Yu Y, Zhang M, Liu S, Xu H, Guo Z, Cheng T and Cao X: Notch1 signaling inhibits growth of human hepatocellular carcinoma through induction of cell cycle arrest and apoptosis. Cancer Res 63: 8323-8329, 2003.

21. Wang C, Qi R, Li N, Wang Z, An H, Zhang Q, Yu Y and Cao X: Notch1 signaling sensitizes TRAIL-induced apoptosis in human hepatocellular carcinoma cells by inhibiting Akt/Hdm2-mediated p53 degradation and up-regulating p53-dependent DR5 expression. J Biol Chem 284: 16183-16190, 2009.

22. Xu J, Yun X, Jiang J, Wei Y, Wu Y, Zhang W, Liu Y, Wang W, Wen $Y$ and $G u J$ : Hepatitis B virus $X$ protein blunts senescence-like growth arrest of human hepatocellular carcinoma via reducing Notch1 cleavage. Hepatology 52: 142-154, 2010. 
23. Wang K, Liu J, Yan ZL, Li J, Shi LH, Cong WM, Xia Y, Zou QF, $\mathrm{Xi}$ T, Shen F, et al: Overexpression of aspartyl-(asparaginyl)$\beta$-hydroxylase in hepatocellular carcinoma is associated with worse surgical outcome. Hepatology 52: 164-173, 2010.

24. Sobin LH and Wittekind C (eds): TNM Classification of Malignant Tumors. 6th edition. Wiley-Liss, New York, pp81-83, 2002.

25. Llovet JM, Di Bisceglie AM, Bruix J, Kramer BS, Lencioni R, Zhu AX, Sherman M, Schwartz M, Lotze M, Talwalkar J, et al; Panel of Experts in HCC-Design Clinical Trials: Design and endpoints of clinical trials in hepatocellular carcinoma. J Natl Cancer Inst 100: 698-711, 2008.

26. Talwalkar JA and Gores GJ: Diagnosis and staging of hepatocellular carcinoma. Gastroenterology 127 (Suppl 1): S126-S132, 2004.

27. Yamamoto J, Kosuge T, Saiura A, Sakamoto Y, Shimada K, Sano T, Takayama T, Sugawara Y, Yamaguchi T, Kokudo N, et al: Effectiveness of hepatic resection for early-stage hepatocellular carcinoma in cirrhotic patients: Subgroup analysis according to Milan criteria. Jpn J Clin Oncol 37: 287-295, 2007.

28. Mazzaferro V, Regalia E, Doci R, Andreola S, Pulvirenti A Bozzetti F, Montalto F, Ammatuna M, Morabito A and Gennari L: Liver transplantation for the treatment of small hepatocellular carcinomas in patients with cirrhosis. N Engl J Med 334: 693-699, 1996.

29. Vauthey JN, Lauwers GY, Esnaola NF, Do KA, Belghiti J, Mirza N, Curley SA, Ellis LM, Regimbeau JM, Rashid A, et al: Simplified staging for hepatocellular carcinoma. J Clin Oncol 20: 1527-1536, 2002 .

30. Yin L, Velazquez OC and Liu ZJ: Notch signaling: Emerging molecular targets for cancer therapy. Biochem Pharmacol 80: $690-701,2010$
31. Weng AP, Millholland JM, Yashiro-Ohtani Y, Arcangeli ML, Lau A, Wai C, Del Bianco C, Rodriguez CG, Sai H, Tobias J, et al: $c-M y c$ is an important direct target of Notch1 in T-cell acute lymphoblastic leukemia/lymphoma. Genes Dev 20: 2096-2109, 2006.

32. Rangarajan A, Talora C, Okuyama R, Nicolas M, Mammucari C, Oh H, Aster JC, Krishna S, Metzger D, Chambon P, et al: Notch signaling is a direct determinant of keratinocyte growth arrest and entry into differentiation. EMBO J 20: 3427-3436, 2001.

33. Nicolas M, Wolfer A, Raj K, Kummer JA, Mill P, van Noort M, Hui CC, Clevers H, Dotto GP and Radtke F: Notch1 functions as a tumor suppressor in mouse skin. Nat Genet 33: 416-421, 2003.

34. Wang M, Xue L, Cao Q, Lin Y, Ding Y, Yang P and Che L: Expression of Notch1, Jagged 1 and $\beta$-catenin and their clinicopathological significance in hepatocellular carcinoma. Neoplasma 56: 533-541, 2009.

35. Bruix J and Llovet JM: Prognostic prediction and treatment strategy in hepatocellular carcinoma. Hepatology 35: 519-524, 2002.

36. Sun HC, Tang ZY, Li XM, Zhou YN, Sun BR and Ma ZC: Microvessel density of hepatocellular carcinoma: Its relationship with prognosis. J Cancer Res Clin Oncol 125: 419-426, 1999.

37. Poon RT, Ng IO, Lau C, Yu WC, Yang ZF, Fan ST and Wong J: Tumor microvessel density as a predictor of recurrence after resection of hepatocellular carcinoma: A prospective study. J Clin Oncol 20: 1775-1785, 2002.

38. Leong KG, Niessen K, Kulic I, Raouf A, Eaves C, Pollet I and Karsan A: Jagged1-mediated Notch activation induces epithelialto-mesenchymal transition through Slug-induced repression of E-cadherin. J Exp Med 204: 2935-2948, 2007. 